\title{
Evaluasi Kualitas Udara Dengan Mengukur Kadar Total Suspended Particulate (TSP) di Laboratorium Akrilik Program Studi D III Teknik Gigi
}

\author{
Suryani Catur Suprapti ${ }^{1}$, Aryudhi Armis ${ }^{2}$ \\ 1,2 Jurusan Teknik Gigi, Politeknik Kesehatan Tanjung karang, Indonesia
}

\begin{abstract}
Abstrak
Laboratorium pendidikan merupakan unit penunjang akademik pada lembaga pendidikan. Laboratorium pendidikan teknik gigi dibedakan menjadi: laboratorium akrilik, laboratorium logam, dan laboratorium keramik/porselen. Bahan dasar akrilik adalah metil metakrilat (MMA). MMA dilaporkan dapat menjadi faktor iritan bagi paru-paru, kulit maupun mata. Tujuan penelitian yang akan dilakukan adalah: untuk mengetahui nilai TSP sebelum praktikum, selama praktikum dan setelah praktikum di laboratorium akrilik, untuk mengetahui kualitas udara sebelum, selama, dan setelah praktikum, serta untuk mengetahui perbedaan kualitas udara sebelum praktikum, selama praktikum, sesudah praktikum pada kondisi tanpa perlakuan dan dengan perlakuan . Jenis penelitian yang digunakan adalah penelitian non eksperimental yang bersifat deskriptif analitik. Pengumpulan data dilakukan dengan teknik data primer, yaitu kadar debu (TSP) sebelum, selama, dan setelah praktikum. Penelitian akan dilakukan di Laboratorium Akrilik Jurusan Teknik Gigi, Poltekkes Kemenkes Tanjung Karang pada bulan Agustus-Desember 2019. Teknik sampling yang digunakan purposive sampling dengan jumlah sebanyak 18 sampel. Data ditampilkan dalam bentuk tabel distribusi frekuensi dan uji $t$ independen untuk melihat perbedaan kadar TSP sebelum, selama, dan sesudah praktikum dilaksanakan. Hasil penelitian menunjukkan bahwa jumlah Total Suspended Particulate (TSP) di laboratorium akrilik jurusan teknik gigi masih masih tergolong baik. Dari seluruh waktu pengukuran hanya pada saat pagi hari yang terdapat perbedaan secara bermakna antara kelompok perlakuan dan tanpa perlakuan.
\end{abstract}

Kata kunci: kualitas udara, TSP. Akrilik

\section{Air Quality Evaluation By Measuring Total Suspended Particulate (TSP) Levels in Acrylic Laboratories D III Dental Engineering Study Program}

\begin{abstract}
Educational laboratories are academic support units in educational institutions. Dental engineering education laboratories are divided into: acrylic laboratories, metal laboratories, and ceramic / porcelain laboratories. The basic material of acrylic is methyl methacrylate (MMA). MMA is reported to be an irritant factor for the lungs, skin and eyes. The research objectives will be carried out: to find out the value of TSP before practicum, during practicum and after practicum in acrylic laboratories, to find out air quality before, during, and after practicum, and to find out the difference in air quality before practicum, during practicum, after practicum in conditions without treatment and with treatment. This type of research is a non-experimental research that is descriptive analytic. Data collection was carried out using primary data techniques, namely dust content (TSP) before, during, and after practicum. The research will be conducted in the Acrylic Laboratory of the Dental Engineering Department, Tanjung Karang Health Poltekkes in August-December 2019. The sampling technique used was purposive sampling with a total of 18 samples. The data is displayed in the form of a frequency distribution table and independent t-test to see differences in the levels of TSP before, during and after practicum. The results showed that the total number of Suspended Particulate (TSP) in acrylic laboratories majoring in dental engineering was still relatively good. Of all the measurement times only in the morning there were significant differences between the treatment groups and without treatment.
\end{abstract}

Keywords: air quality, TSP. acrylic

Korespondensi: Suryani Catur Suprapti, Jurusan Teknik Gigi Politeknik Kesehatan Tanjungkarang, Jalan Soekarno-Hatta No. 1 Hajimena Bandar Lampung, mobile 081394322013, e-mail 6atikko6@gmail.com 


\section{Pendahuluan}

Tuntutan global terhadap mutu pendidikan membawa konsekuensi untuk memperkuat penguasaan Ilmu Pengetahuan dan Teknologi (IPTEK), khususnya pembelajaran praktik di laboratorium. Hal ini dikarenakan lulusan diploma (D) III diharuskan mempunyai kompetensi untuk menerapkan materi yang sudah dipelajari dikelas (PPSDM). Dalam menunjang proses pembelajaran yang teratur dan berkelanjutan, dan juga setiap institusi pendidikan wajib memiliki prasarana yang meliputi lahan, ruang kelas, ruang pimpinan, ruang pendidik, ruang tata usaha, ruang perpustakaan, ruang laboratorium, ruang bengkel kerja, instalasi daya dan jasa, tempat berolah raga, tempat beribadah dan tempat ruang lain yang diperlukan untuk menunjang proses pembelajaran yang teratur dan berkelanjutan. (Peraturan Pemerintah Republik Indonesia (PP RI) No.19 Tahun 2005 tentang Standar Nasional Pendidikan ). Berdasarkan PP RI No. 19 tahun 2005, maka Prodi DIII tenaga kesehatan perlu memiliki laboratorium yang sesuai standar.

Laboratorium pendidikan merupakan unit penunjang akademik pada lembaga pendidikan, untuk kegiatan pengujian, kalibrasi, dan/atau produksi dalam skala terbatas, dengan menggunakan peralatan dan bahan berdasarkan metode keilmuan tertentu, dalam rangka pelaksanaan pendidikan, penelitian, dan pengabdian kepada masyarakat. Laboratorium pendidikan teknik gigi memliki persyaratan tertentu: bentuk ruang bujursangkar, ruang kerja minimal 2,5 $\mathrm{m} 2 /$ orang, dengan ruang penyimpanan alat dan bahan terpisah dari ruang kerja, terdapat ruang kosong antara meja dan tembok berjarak $1,7 \mathrm{~m}$. ( Standar Lab Teknik Gigi,2017).

Laboratorium pendidikan teknik gigi dibedakan menjadi: laboratorium akrilik, laboratorium logam, dan laboratorium keramik/porselen. Selama kegiatan pembelajaran praktek pembuatan gigi tiruan di ketiga lab tersebut selalu menghasilkan polutan debu. Pada laboratorium akrilik yang melakukan proses pembuatan gigi tiruan lepasan ( gigi tiruan sebagian atau lenggkap), pembuatan plat ortodonti, pembuatan protesa maksilofasial, pembuatan mahkota jaket akrilik, selama packing, grinding dan finishing paparan debu berlangsung selama kegiatan praktikum.

Bahan dasar akrilik adalah metil metakrilat (MMA). MMA dilaporkan dapat menjadi faktor iritan bagi paru-paru, kulit maupun mata. Saat plat akrilik dihaluskan, dihasilkan debu yang dapat terhirup dan masuk dalam saluran pernafasan dan beresiko untuk terjadinya pneumokoniosis. Pneumokoniosis adalah penyakit paru akibat menghirup partikel debu tertentu yang menyebabkan kerusakan paru atau istilah lainnya adalah occupational lung disease. (ishikawa) Dilaporkan pula efek samping lainnya adalah menimbulan iritasi pada mata, kulit, tenggorok, paru-paru, bahkan sistem syaraf. Uap MMA sebesar $125 \mathrm{ppm}$ dapat menyebabkan mata berair,sakit tenggorok dan batuk. Kontak langsung pada kulit dapat menyebabkan gatal, terbakar, kemerahan, bengkat, retak pada kulit. Bila terjadi kontak kulit dalam jangka panjang dapat meyebabkan kesemutan, mati rasa, memutihnya jari (Ansul chug, 2017). Paparan MMA dapat mengakibatkan hypersensitivity pneumonitis akut, subakut ataupun kronis dengan intensitas tergantung pada jumlah dan lama antigen terhirup (Scherpereel A). Debu akrilik dan uap MMA yang dihasilkan selama pekrjaan laboratorium akan terakmuasi dalam udara ruangan yang mempengaruhi kualitas udara.

Secara umum kualiatas udara dalam ruangan dipengaruhi oleh agen abiotik (partikel debu, kelembaban, suhu dan cahaya), dan biotik (bakteri, jamur, serbuk sari). Menurut Enviromental Protection Agency og America ( EPA) 2010, polusi udara dalam ruangan beresiko terhadap kesehatan manusia. Kualitas udara dalam ruanagn 2-5 kali lebih buruk dibandingkan dengan udara di luar ruangan ( lingkungan bebas). Ventilasi lokal dan umum sangat penting dalam pencegahan dari paparan debu, dan merupakan tindakan pencegahan utama yang harus diambil di tempat kerja. Dimungkinkan untuk mencegah penyakit akibat kerja dengan menjaga nilai debu dalam tingkat yang dapat diterima di tempat kerja. Meskipun berisiko tinggi terpapar debu di lingkungan kerja, penggunaan alat pelindung pribadi oleh teknisi ternyata agak rendah. Tingkat penggunaan masker biasa hanya $70 \%$. Waktu kerja/ pajanan" berperan penting dalam proses transformasi risiko kesehatan menjadi penyakit. Usia kerja awal, jam kerja harian dan mingguan, terutama total waktu kerja dalam profesi memiliki faktor penentu dalam terjadinya penyakit akibat kerja.

Laboratorium pendidikan Program Studi Teknik Gigi Poltekkes Tanjungkarang secara umum masih dalam pengembangan, dan sampai saat ini masih belum memenuhi standar baik dalam luas ruangan, proporsi alat dan jumlah mahasiswa, desain ruangan, pengelolaan 
limbah, jumlah SDM dan jumlah jam kerja. Dengan jumlah mahasiswa dan jam praktikum yang padat sepanjang semester, menjadi penghambat untuk melakukan pembersiha ruangan secara berkala. Sampai saat ini belum ada data atau belum pernah dilakukan pengkajian tentang kualiatas udara dalam ruangan laboratorium tersebut. Dengan kondisi dan kemungkinan dampak dari pajanan debu laboratorium ( debu akrilik) dalam jangka panjang , maka penulis tertarik untuk melakukan penelitian tentang kualitas udara dengan melakukan pemeriksaan TSP di laboratorium pendidikan Program Studi Teknik Gigi Poltekkes Tanjungkarang khususnya laboratorium akrilik.

\section{Metode}

Jenis penelitian yang digunakan adalah penelitian non eksperimental yang bersifat deskriptif analitik. Pengumpulan data dilakukan dengan teknik data primer, yaitu kadar debu akrilik sebelum, selama, dan setelah praktikum dengan dan tanpa perlakuan kipas angin berembun serta exhaust fan di laboratorium akrilik. Penelitian akan dilakukan di Laboratorium Akrilik Jurusan Teknik Gigi, Poltekkes Kemenkes Tanjung Karang. Penelitian dilaksanakan pada semester ganjil tahun ajaran 2019/2020, pada bulan AgustusDesember 2019.

Dalam penelitian ini teknik sampling yang digunakan yaitu nonprobability sampling, dengan teknik purposive sampling. Jumlah sampel yang ditetapkan menurut teknik purposive sampling adalah 18 sampel. Kriteria subjek penelitian ini adalah kualitas udara dengan mengukur kadar TSP di Laboratorium akrilik Jurusan Teknik Gigi.

Instrumen penelitian menggunakan data primer yang diperoleh dari lokasi penelitian, yaitu data kualitas udara yang diukur melalui kadar TSP. Pengolahan dan analisis data menggunakan SPSS versi 16 yang disajikan dalam bentuk tabel. Setelah data terkumpul, dilakukan analisis data menggunakan tabel distribusi frekuensi pada saat sebelum, selama, dan sesudah praktikum. Analsis data digunakan untuk memperoleh data deskriptif dengan distribusi frekuensi seluruh variabel yang akan diteliti, untuk mengetahui perbedaan kualitas udara sebelum, selama, dan sesudah praktium dengan dan tanpa perlakuan kipas angin berembun serta exhaust fan di laboratorium akrilik dengan dilakukan uji $\mathrm{t}$ independen terhadap seluruh variabel yang akan diteliti dan tingkat kemaknaan sebesar 5\%.

Hasil

Hasil pemeriksaan kualitas udara di laboratorium akrilik Jurusan Teknik Gigi Poltekkes Tanjung karang adalah sebagai berikut:

Tabel 1. Jumlah Total Suspended Particulate di laboratorium akrilik Jurusan Teknik Gigi (satuan $\mu \mathrm{g} / \mathrm{m}$ )

\begin{tabular}{|c|c|c|c|}
\hline \multicolumn{2}{|c|}{ Jenis perlakuan } & $\begin{array}{c}\text { Tanpa } \\
\text { perlakuan }\end{array}$ & $\begin{array}{c}\text { Dengan } \\
\text { perlakuan }\end{array}$ \\
\hline \multirow{3}{*}{ Hari ke 1 } & Pagi & 7,84 & 27,2 \\
\cline { 2 - 4 } & Siang & 14,71 & 28,4 \\
\cline { 2 - 4 } & sore & 44,12 & 28,6 \\
\hline \multirow{3}{*}{ Hari ke 2 } & Pagi & 5,88 & 28,2 \\
\cline { 2 - 4 } & Siang & 93,14 & 28,4 \\
\cline { 2 - 4 } & Sore & 21,57 & 28,8 \\
\hline \multirow{3}{*}{ Hari ke 3 } & Pagi & 4,90 & 28,2 \\
\cline { 2 - 4 } & Siang & 7,84 & 28,4 \\
\cline { 2 - 4 } & sore & 15,69 & 28,1 \\
\hline
\end{tabular}

Hasil penelitian pada tabel 1 menunjukkan bahwa jumlah TSP selama waktu pengukuran masih tergolong baik, yaitu kurang dari $75 \mu \mathrm{g} / \mathrm{m}^{3}$. Hasil penelitian ini tidak termasuk ke dalam pencemaran udara. Untuk melihat perbedaan antara jumlah TSP antara kondisi dengan perlakuan dan tanpa perlakuan, maka dilakukan uji t independen.

Hasil uji $t$ independen menunjukkan bahwa pengukuran jumlah TSP di sore hari setelah selesai praktikum, tidak terdapat perbedaan yang bermakna antara tanpa perlakuan dan dengan perlakuan dengan nilai $\mathrm{p}$ $=0,89$. Pengukuran jumlah jumlah TSP di sore hari setelah selesai praktikum, tidak terdapat perbedaan yang bermakna antara tanpa perlakuan dan dengan perlakuan dengan nilai $\mathrm{p}$ $=0,75$, sedangkan jumlah TSP di pagi hari sebelum dimulai praktikum, terdapat perbedaan yang bermakna antara tanpa perlakuan dan dengan perlakuan dengan nilai $\mathrm{p}=0,00$ (Tabel 2). 
Tabel 2. Hasil uji t Independen antara kadar Total Suspended Particulate dengan perlakuan dan tanpa perlakuan

\begin{tabular}{|c|c|c|c|c|}
\hline \multicolumn{2}{|c|}{$\begin{array}{c}\text { Jenis } \\
\text { perlakuan }\end{array}$} & $\begin{array}{c}\text { Tanpa } \\
\text { perlakuan }\end{array}$ & $\begin{array}{c}\text { Dengan } \\
\text { perlakuan }\end{array}$ & $\mathrm{P}$ \\
\hline \multirow{2}{*}{$\begin{array}{c}\text { Hari } \\
\text { ke } 1\end{array}$} & Pagi & 7,84 & 27,2 & \multirow{2}{*}{0,00} \\
\cline { 2 - 4 } & Siang & 14,71 & 28,4 & \\
\cline { 2 - 4 } \multirow{2}{*}{$\begin{array}{c}\text { Hari } \\
\text { ke 2 }\end{array}$} & Pore & 44,12 & 28,6 & \\
\cline { 2 - 4 } & Siang & 5,88 & 28,2 & \multirow{2}{*}{0,75} \\
\cline { 2 - 4 } Hari & Sore & 21,57 & 28,4 & \\
ke 3 & Pagi & 4,90 & 28,2 & \multirow{2}{*}{0,89} \\
\cline { 2 - 4 } & Siang & 7,84 & 28,4 & \\
\hline
\end{tabular}

\section{Pembahasan}

Penelitian ini dilakukan di laboratorium akrilik Jurusan Teknik Gigi Poltekkes Kemenkes Tanjung Karang. Jenis penelitian yang dilakukan adalah penelitian non eksperimental yang bersifat dseskriptif analtik. Pengumpulan data dilakukan dengan mengambil data penelitian secara langsung. Subjek penelitian adalah jumlah Total Suspended Particulate (TSP) yang didapat di laboratorium akrilik Jurusan Teknik Gigi.

Penelitian dilakukan beberapa bulan dengan jumlah sampel sebanyak 18 buah. Penelitian ini dilakukan selama tiga hari pada kelompok tanpa perlakuan dan tiga hari pada kelompok dengan perlakuan. Setiap harinya dilakukan tiga kali pengambilan sampel, yaitu pada pagi, siang, dan sore hari. Pada kondisi tanpa perlakuan secara nominal kadar TSP di laboratorium akrrilik akan meningkat dari pagi hari sampai sore hari, pada hari pertama dan kedua, namun terjadi penurunan kadar TSP di hari ke tiga. Penurunan ini dimungkinkan karena pada hari ke tiga terjadi pemadaman listrik PLN sehingga kegiatan praktikum sempat terhenti beberapa jam. Dengan terhentinya kegiatan praktikum secara otomatis debu yang dihasilakan dari kegiatan praktikum berkurang. Pada hari praktikum dengan perlakuan kadar TSP hampir sama untuk pengukuran pagi hari, siang serta sore hari.

Berdasarkan hasil uji $t$ independen, tidak terdapat perbedaan yang bermakana antara kelompok tanpa perlakuan dan dengan perlakuan saat siang dan sore hari. Hal ini mungkin terjadi karena ketika siang dan sore hari adalah saat-saat praktikum sedang berjalan atau dipuncak aktivitas, sehingga jumlah TSP yang diukur bisa dikatakan sama secara statistik. Hal ini juga bisa terjadi karena pada saat pengukuran, mobilitas praktikan masih tinggi, dan beberapa kali udara di ruangan berkontak dengan udara luar. Hasil pengukuran jumlah TSP pada pagi hari menunjukkan hasil perbedaan yang bermakna secara statistik. Hal ini mungkin dikarenakan belum ada aktivitas di ruang laboratorium. Saat ruangan diberi perlakuan dengan kipas berembun, maka debu yang ada akan terangkat/ melayang, sehingga dengan mudah dihisap dan dikumpulkan.

Terdapat beberapa keterbatasan dalam penelitian ini; mobilitas praktikan yang tidak dapat terkontrol sehingga ruangan tidak dapat terisolasi dengan baik. Selanjutnya desain penempatan exhaust fan dan kipas angin kurang mampu mengumpulkan debu serta menghisap debu dengan cepat. Kendala rusaknya beberapa alat poles menyebabkan kegiatan praktikum tidak berjalan dengan maksimal sehingga memungkinkan kadar TSP yang terukur lebih kecil dari yang semestimya apabila semua alat berfungsi dan kegiatan praktikum mencapai puncaknya.

Setelah dilakukan serangkaian penelitian, maka dapat diambil simpulan sebagai berikut: Jumlah TSP di laboratorium akrlik sebelum, selama, dan sesudah kegiatan praktikum ratarata dibawah $75 \mu \mathrm{g} / \mathrm{m}^{3}$, baik pada kelompok tanpa perlakuan, maupun dengan perlakuan. Jumlah TSP di laboratorium akrlik sebelum, selama, dan sesudah kegiatan praktikum berlangsung belum termasuk ke dalam kategori pencemaran udara atau dengan kata lain, masih tergolong baik. Jumlah TSP yang terdapat di laboratorium akrilik, tidak terdapat perbedaan yang bermakna, yaitu pada saat siang dan sore hari, sedangkan pada saat pagi hari, terdapat perbedaan yang bermakna antara kelompok tanpa perlakuan dan dengan perlakuan.

\section{Daftar Pustaka}

Alavi Ali,et all. Respiratory Findings in Dental Laboratory Technicians in Rasht (North of Iran). (C2011 NRITLD, National Research Institute of Tuberculosis and Lung Disease, Iran. Tanaffos (2011) 10(2), 44-49

Anshul Chugh* Occupational Hazards in Prosthetic Dentistry. Dentistry, an open access journal ISSN:2161-1122 .Volume $7 \cdot$ Issue $2 \cdot 2161-1122-6-410$

Alfiah, Taty.M.T. Pencemaran Udara(Edisi Revisi). Teknik Lingkungan.Institut Teknlogi Adhitama Surabaya. 2009 
Belk1s Yurdasal.2014. The evaluation of the dust-related occupational respiratory disorders of dental laboratory technicians working in Denizli Province

Badan Standarisasi Nasional. 2005. Cara Uji Parikel Tersuspensi Total Menggunakan Peralatan High Volume Air Sampler (HVAS) dengan Metoda Gravimetri. SNI 19- 7119.3-2005

Cazier F, Dewaele D, Delbende A, Nouali H, Garcon G, Verdin A, Courcot D, Bouhsina S, Shirali P. 2011. Sampling analysis and characterization of particle in the atmosphere of rural, urban, and industrial areas. J 227.-Environmental Science. 4: 218

Departemen Kesehatan, DitjenPPM \&PL., 2001, Parameter Pencemar UdaraDan Dampaknya Terhadap Kesehatan,, Jakarta, (hal. 18).

Ergun Dilek, et all. 2014. Pneumoconiosis and respiratory problems in dental laboratory technicians : analysis of 893 dental technicians. International Journal of occupational medicine and enviromental health. Vol. 27.issue 5. Pg. 785-796.

Formenti P, Schutz L, Balkanski Y, Desboeufs K, Ebert M, Kandler K, Petzold A, Scheuvens D, Weinbruch S, Zhang D. 2011. Recent progress in understanding physical and chemical properties of african and asian mineral 8256. doi:10.5194/acp- 11-8231-2011.-dust. Journal of Atmosphere Chemical Physics. 11: 8231

Goenharto Sianiwati. 2016. Bahaya bagi teknisi dental laboratorium pada pembuatan peranti ortodonti lepasa. Jurnal PDGI Vol. 65, No. 1, Januari-April 2016 | Hal. 6-11 | ISSN 0024-9548

Goenharto, Sianiwati et all . Personal Protective Equipment for Acrylic Workers at Dental Laboratories in Surabaya, Indonesia. Journal of International Dental and Medical Research ISSN 1309-100X http://www.jidmr.com

Hina Toufique. 2017. Work Place Related Health Hazards Among Dental
Laboratory Technicians In Karachi. JPDA Vol. 26 No. 04 Oct-Dec 2017: 1-8.

Hidayat, Syaiful dkk. 2012. Pengaruh Polusi Udara dalam Ruangan Terhadap Paru. Continuing Medical Education. Universitas Indonesia : Jakarta

Haritash AK, Kaushik CP. 2006. Assessment of Seasonal Enrichment of Heavy Metals in Respirable Suspended Particulate Matter of a Sub-Urban Indian City. Environ Monit Assess 128:411-420. DOI 10.1007/s10661-006-9335-1.

Jusuf,Anwar dan Wahyu Aniwidianingsih., Pengaruh Polusi Udara Terhadap Kesehatan, Makalah disampaikanpada Lokakarya Strategi Penurunan Emisi Kendaraan Terintegrasi,Jakarta, $16-18$ Oktober2001.

Kemenkes RI. 2017.Standar Laboratorium Diploma Teknik Gigi. Badan PPSDM Kes. Jakarta

Karar K, Gupta AK, Kumar A, Biswas AK. 2006. Seasonal Variations of PM10 and TSP in Residential and Industrial Sites in An Urban Area of Kolkata, India. Environmental Monitoring and Assessment 118: 369-381. DOI: 10.1007/s10661-006-1503-9.

Mukono. Pencemaran Udara dan Pengaruhnya Terhadap Gangguan Saluran Pernafasan. Surabaya: Airlangga University Press; 2003.

Nagpal, Jitendra J.Shah Tanvi.,1997, 'Urban Air Quality Management Strategy in Asia', Jakarta Report URBAIR, World Bank Technical Paper No. 379, The World bank, Washington, D.C.

Peraturan Menteri Kesehatan Republik Indonesia Nomor 32 Tahun 2015 Tentang Standar Pelayanan Keteknisian . www.peraturan.go.id

Puskar T, Ilic M, Budak I, Vukelic D, Trifkovic B, Hodolic .J. Environmental and occupational health risks in dental laboratories. 5th International Quality Conference May 20th 2011; p. 595-602. 
Prasasti, Corie Indria, J. Mukono, dkk. 2005. Pengaruh Kualitas Udara Dalam Ruangan Ber-AC Terhadap gangguan Kesehatan. Fakultas Kesehatan Masyarakat. Surabaya : Universitas Airlangga.

Peraturan Pemerintah No. 41 Tahun 1999 Tentang Pengendalian Pencemaran Udara.

Peraturan Menteri Kesehatan RI No. 1077/MENKES/PER/V/2011 Tentang Pedoman Penyehatan Udara Dalam Ruang Rumah.

Putra, prawira. Adi. Tingkat Pencemaran Udara Kawasan Sekolah Berdasarkan Para Meter Total Suspended Particulate (TSP) DanKebisingan Akibat Kendaraan Yang Melintas. Program Studi TeknikLingkungan Fakultas Tekni Universitas Indonesia.2011.

Peraturan Pemerintah No 41 tahun 2006. Baku Mutu Udara AmbienNasional. Pengendalian Pencemaran Udara. 2006.

Ratnasari, Yanida. 2012. Analisis Resiko Cemaran Debu (TSP) Akibat Asap Pabrik Terhadap Pekerja dan Masyarakat Sekitar (Studi Kasus : PT. INti General Yaja Steel Semarang). Fakultas Teknik. Semarang : Universitas Diponegoro.

Smith JL, Lee K. 2003. Soil as a source of dust and implications for human health. Advances in Agronomy. 80: 1

Soedomo, Moestikahadi. 2001. Pencemaran Udara (Kumpulan Karya Ilmiah). Bandung : ITB.

SNI. 19-7119.3-2005. Udara Ambien Bagian 3 "Cara Uji Partikel Tersuspensi Total Menggunakan Peralatan High Volume Air Sampler (HVAS) dengan Metode Gravimetri”. Bagian Kesehatan Lingkungan Fakultas Kesehatan Masyarakat Universitas Diponegoro.2015.

Srikandi Fardiaz, 1992 , Polusi Air dan Udara, Penerbit Kanisius , Yogyakarta.

Shanty MF Syahril,2003., 'Kualitas Udara Sepuluh Kota di Indonesia Mengkhawatirkan', Dialog Publik "Udara Bersih, Hak Kita Bersama",30 Juli 2003,
Jakarta ,K, 31/7/2003 No. 034 Tahun ke39 hal. 9.

Seinfeld JH, Pandis SN. 2006. Atmospheric Chemistry and Physics: From Air Pollution to Climate Change, 2nd ed. John Wiley \& Sons. USA.

The University of Queenland, 1997, Source Emission Training Manual $\mathrm{H}-43$, Regional Environmental Health Laboratory Development Project, Technical Training, Australia.

Tri Tugaswati,A., Sukar,Athena Anwar, dan sri Soewasti Soesanto,1996. Pemantauan Kualitas Udara Di Daerah Rawasari dan Pulo Gadung, Jakarta. B.Penelitian Kesehatan, vol. 24 No. I —1996 (hal.2).

World at work: Prosthodontics Dental laboratory Technicians. N Torbica, S Krstev. www.occenvmed.com

Wardhana, A.W.Dampak Pencemaran Lingkungan. Yogyakarta : ANDI.2001.

Yulaekah, Siti. Paparan Debu Terhirup Dan Gangguan Fungsi Paru PadaPekerja Industry Batu Kapur (Studi Di Desa Mrisis KecamatanTanggungharjo Kabupaten Grobogan). Thesis. Program Pasca SarjanaUndip Semarang. 2007.

Zhao Y, Shi D. 2012. Analysis of Total Suspended Particulates Pollution along Shanghai-Nanjing Expressway. Open Journal of Air Pollution, 2012, 1, 31-36.

Zhou XL. 2010. Discussion on Some Terms Used for Sand Dust Weather in the National Standard. Scientia Meteorologica Sinica, Vol. 30, No. 2, pp. 234-238. 